\title{
GCU
}

Glasgow Caledonian

University

University for the Common Good

\section{Generic closed loop controller for power regulation in dual active bridge DC-DC converter with current stress minimization}

Hebala, Osama M.; Aboushady, Ahmed A.; Ahmed, Khaled; Abdelsalam, Ibrahim

Published in:

IEEE Transactions on Industrial Electronics

DOI:

10.1109/TIE.2018.2860535

Publication date:

2019

Document Version

Author accepted manuscript

Link to publication in ResearchOnline

Citation for published version (Harvard):

Hebala, OM, Aboushady, AA, Ahmed, K \& Abdelsalam, I 2019, 'Generic closed loop controller for power regulation in dual active bridge DC-DC converter with current stress minimization', IEEE Transactions on Industrial Electronics, vol. 66, no. 6, pp. 4468 - 4478. https://doi.org/10.1109/TIE.2018.2860535

\section{General rights}

Copyright and moral rights for the publications made accessible in the public portal are retained by the authors and/or other copyright owners and it is a condition of accessing publications that users recognise and abide by the legal requirements associated with these rights.

Take down policy

If you believe that this document breaches copyright please view our takedown policy at https://edshare.gcu.ac.uk/id/eprint/5179 for details

of how to contact us. 


\title{
Generic Closed Loop Controller for Power Regulation in Dual Active Bridge DC/DC Converter with Current Stress Minimization
}

\author{
Osama M. Hebala, Ahmed A. Aboushady, Senior Member, IEEE, Khaled. H. Ahmed, Senior Member, IEEE \\ and Ibrahim Abdelsalam
}

\begin{abstract}
This paper presents a comprehensive and generalized analysis of the bidirectional dual active bridge (DAB) DC/DC converter using triple phase shift (TPS) control to enable closed loop power regulation while minimizing current stress. The key new achievements are: a generic analysis in terms of possible conversion ratios/converter voltage gains (i.e. Buck/Boost/Unity), per unit based equations regardless of DAB ratings, and a new simple closed loop controller implementable in real time to meet desired power transfer regulation at minimum current stress. Per unit based analytical expressions are derived for converter AC RMS current as well as power transferred. An offline particle swarm optimization (PSO) method is used to obtain an extensive set of TPS ratios for minimizing the RMS current in the entire bidirectional power range of -1 to 1 per unit. The extensive set of results achieved from PSO presents a generic data pool which is carefully analyzed to derive simple useful relations. Such relations enabled a generic closed loop controller design that can be implemented in real time avoiding the extensive computational capacity that iterative optimization techniques require. A detailed Simulink DAB switching model is used to validate precision of the proposed closed loop controller under various operating conditions. An experimental prototype also substantiates the results achieved.
\end{abstract}

Index Terms - Current stress, Dual active bridge (DAB), Particle swarm optimization (PSO), Triple phase shift (TPS).

\section{INTRODUCTION}

$\mathrm{D}$ UAL active bridge (DAB), originally proposed in the 1990s [1], significantly attracted researchers among several bidirectional DC/DC converters [2] such as dualflyback, dual-Cuk, Zeta-Sepic, forward-flyback, dual-pushpull, push-pull-forward, push-pull-flyback and dual-halfbridge. This is mainly due to its high power handing capability, zero voltage switching (ZVS) characteristics, high power density, galvanic isolation in transformer based versions and the possibility of cascaded or modular configuration to enable higher power/higher voltage designs [3-7]. Due to these advantages, DAB DC/DC converters have attracted more attention in power energy conversion applications, such as dc microgrids, medium voltage dc (MVDC) and high voltage dc (HVDC) transmission systems [8-10].

Manuscript received Jan. 17, 2018; revised Apr. 21, 2018. Accepted for publication July 3, 2018. Osama M. Hebala is with School of Engineering, Robert Gordon University, Aberdeen, UK, on leave from Arab Academy for Science and Technology and Maritime Transport, Alexandria, Egypt. Ahmed A. Aboushady is with School of Engineering and Built Environment, Glasgow Caledonian University, Glasgow, UK. K.H. Ahmed is with the EEE department, University of Strathclyde, Glasgow, UK, on leave from the Department of Electrical Engineering, Faculty of Engineering, Alexandria University, Egypt. Ibrahim Abdelsalam is with the Electrical Engineering Department, Arab Academy for Science and Technology and Maritime Transport, Cairo, Egypt. (E-mail: o.m.a.m.hebala@rgu.ac.uk, ahmed.aboushady@ieee.org, khaled.ahmed@ieee.org, I.abdelsalam@aast.edu)
In addition, $\mathrm{DAB} \mathrm{DC} / \mathrm{DC}$ converters have been widely used in distributed generating systems incorporating variable-nature energy resources, such as PV or wind, for voltage matching/stepping and accommodating power regulation between energy storage systems, energy sources and load demands [11-14].

Studies have been on going to analyze, control and improve the overall performance of the DAB converter. Phase shift control techniques are the most common modulation schemes in literature due to their implementation simplicity, fundamental frequency operation which reduces switching losses, uniform conduction of switching devices, enabling of ZVS operation and non-active power circulation control within converter $[2,3$, 14]. The conventional phase shift (CPS), or single phase shift (SPS), was the first proposed technique [1] where the phase shift angle between the two active bridges controls the power flow. Then, dual phase shift (DPS) modulation technique was introduced in [15] by adding the same inner phase shift to the bridge voltages to overcome the phenomenon of backflow power that appeared when using CPS. Extended phase shift (EPS) was proposed [16] in order to extend the ZVS range of the $\mathrm{DAB}$ converter, by controlling the duty cycle of one of the bridge voltages. The above mentioned modulation techniques (SPS, DPS and EPS) share a common drawback which is not exploiting all possible control variables which results in reduced efficiency of DAB operation. In this regard, Triple phase shift (TPS) [17-19] introduces an additional control variable which can lead to further improvement of ZVS range and reducing the overall losses hence increasing the efficiency. TPS control utilizes the phase shift angle between the bridges in addition to inner phase shifts at both bridges separately which makes TPS the most general modulation control [20]. A full performance analysis of DAB under TPS control as well as detailed analytical derivations and operational constraints for all possible switching modes were presented in $[20,21]$ where the voltage conversion is not included in the proposed model which is a major drawback. Considering the aforementioned literature, generalized per unit TPS-based DAB model including the converter voltage conversion ratio is overlooked.

Currently, there is a strong trend toward improving the $\mathrm{DAB}$ DC/DC converter efficiency while maintaining the power transfer flow control. Different technical aspects can be considered for minimizing overall DAB losses such as nonactive power losses [22, 23] and current stresses [16, 18, 24, 25]. Non-active power loss minimization was tackled in [22] for DAB where the inductor current was analyzed to obtain an operating range where phase shifts achieving minimum non- 
active power loss can be realized for light and heavy loads in boost operation. However the model was based on the extended phase shift (EPS) modulation technique which result in local optimal operating points at light loads. An iterative algorithm has been proposed in [23] to search for TPS control variables that satisfy the desired active power flow while achieving minimum reactive power consumption. The proposed controller works in an open loop approach with no feedback informing whether actual desired power level is achieved or not. In addition, the method is not generalized for buck and boost DAB operating modes. Authors in [24] used Lagrange Multiplier method to calculate the optimal phase shift ratios for any given power level targeting minimum current stresses defined as RMS inductor current. However, the three proposed converter switching modes do not cover the entire bidirectional power range but only cover operation from -0.5 to $1 \mathrm{pu}$, therefore the proposed scheme cannot be considered universal. An analytical method based on Karush-Kahn-Tucker method was developed in [18] to get the global optimal control parameters achieving minimum RMS current stresses for DAB under a modified TPS control where the outer phase shift between the fundamental components of bridges voltage is introduced. However, the analysis is based on fundamental frequency analysis where the square bridge voltages of the $\mathrm{DAB}$ are replaced by the fundamental frequency components. This ignores the effect of higher order harmonics on effective increase of RMS current. In other cases, the researchers focused on minimizing the per unit peak current in [16] and [25]. Considering the aforementioned literature, RMS inductor current can be considered to be the most effective amongst other minimization objectives such as non-active power loss, peak or average inductor current. This is due to the fact that RMS current stresses have a direct impact on the conduction losses which are considered to be the dominant portion of losses [26, 27]. In addition, conduction and copper losses are proportional to the square of the RMS current [28].

Now, it is a quite clear from literature that the shortcomings in previous DAB current optimization researches can be summarized as follows: non-generalized per unit analysis, discarding the effect of converter voltage gain with bidirectional power flow, cumbersome analysis in some cases, achieving local minimal solutions in some cases due to restricting optimization to a specific control technique or load range and finally impracticality of some derived controllers for real time implementation. It is obvious that no work has completely tackled all challenges simultaneously and most importantly without compromising on level of control complexity and implementing optimization in real time. This paper has identified this research gap therefore proposing an all-round universal solution to the mentioned shortcomings.

The paper comprises 7 sections. Section 2 covers the generalized per unit DAB model under TPS control. Sections 3 and 4 present the offline optimization process that was carried out by applying PSO to the derived per unit DAB model to obtain the global optimal phase shift ratios for minimizing RMS current at full power range for different converter voltage gains. The outcome from the optimization process is a generalized relation between desired power transfer and the optimal phase ratios as a function of the voltage conversion ratio. This generalized relation is used for designing a novel simple closed loop controller which is discussed in detail in section 5 . Afterwards, extensive results from simulation and a low scaled experimental prototype are presented in sections 6 and 7 respectively to validate the proposed controller.

\section{GENERALIZED PER UNIT ANALYSIS OF DAB UNDER TPS CONTROL}

The DAB circuit diagram is presented in Fig. 1. Transformerless version is studied in this paper to simplify analysis which will not change if transformer is inserted as magnetizing inductance is usually neglected and equivalent leakage inductance plays the same role as interface inductor $L$ in Fig. 1. Fig. 2 shows the typical AC voltage/current waveforms of DAB under TPS control. $D_{1}, D_{2}$ and $D_{3}$ are the three phase shift ratios obtained using classical phase shifting of gate signals $S_{1}-S_{4}$ and $\mathrm{Q}_{1}-\mathrm{Q}_{4}$ such that $0 \leq D_{1} \leq 1,0 \leq D_{2} \leq 1,-1 \leq D_{3} \leq 1$. The ratios are normalized with respect to half the switching cycle $\left(T_{h}\right)$. The ratio $D_{l}$ represents the pulse width of the first bridge voltage waveform $\left(v_{b r l}\right)$, and similarly, ratio $D_{2}$ represents the pulse width of the second bridge voltage waveform $\left(v_{b r 2}\right)$. Ratio $D_{3}$ is the phase shift between positive going edge of $v_{b r l}$ and positive going edge of $v_{b r 2}$. Based on all possible combinations between $D_{1}, D_{2}$ and $D_{3}$ that would result in different inductor current waveforms in the bidirectional power range, a total of twelve switching modes can be derived. The twelve operating modes are generically considered in this paper and their typical operating waveforms are illustrated in Table I. A factor $K$ is used to describe the voltage conversion ratio (or converter voltage gain) where $K=V_{d c 2} / V_{d c 1}$ and $K<1$ represents buck/boost mode. In the proposed generalized DAB analysis, all expressions derived are function of $\left(D_{1}, D_{2}, D_{3}\right.$ and $\left.K\right)$. For generalized per unit analysis, base values are selected as voltage $V_{\text {base }}=V_{d c l}$, impedance $Z_{\text {base }}=8 f_{s} L$ where $f_{s}$ is the switching frequency and time of $T_{h}$ (half period).

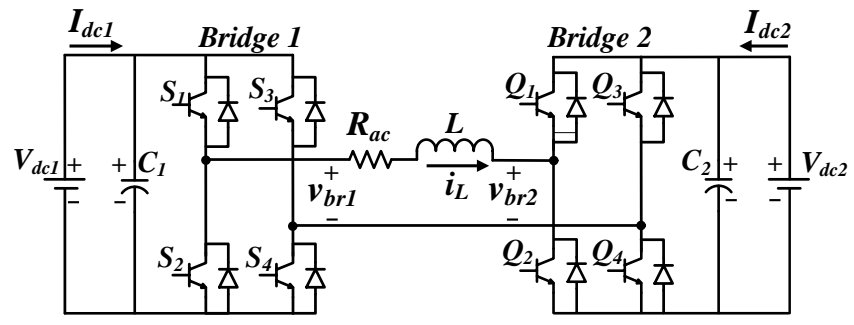

Fig. 1. DAB Circuit Diagram.

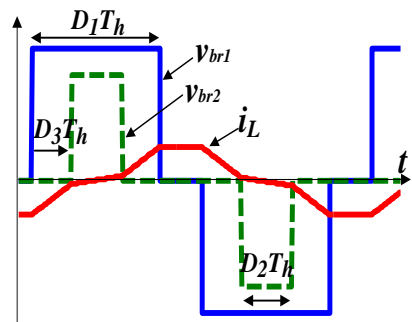

(a)

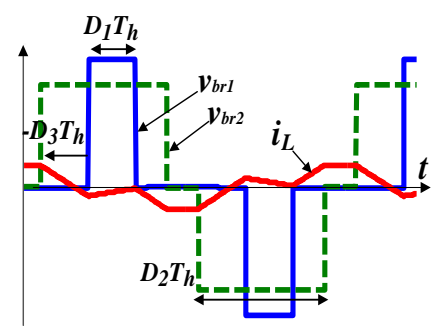

(b)
Fig.2. Examples of voltage and currents waveforms for TPS control:

(a) Forward (+ve) power flow, and (b) Reverse (-ve) power flow.

\section{A. Power Transfer Characteristic}

DAB converter's equivalent circuit model is shown in Fig. 3. Average power transferred by the DAB converter can be 
calculated at either bridge by assuming a lossless inductor. Per unit power for each mode is presented in Table I which is obtained from (1) with piecewise consideration of the voltage and current waveforms over half the period. The operational constraints for each mode in Table I are applied to the derived power equations and the power ranges associated with the modes are therefore achieved.

$$
P=\frac{1}{T_{h}} \int_{0}^{T_{h}} v_{b r 1}(t) \cdot i_{L}(t) d t
$$

\section{B. RMS Inductor Current}

Taking $I_{\text {base }}=V_{\text {base }} / Z_{\text {base }}$, the normalized positive half cycle current instants for each mode are shown in Table II to be used for power and RMS current calculations. A generalized expression for squared RMS inductor current can be developed from (2) by examining the waveforms of inductor currents in the twelve switching modes shown in Table I.

$$
i_{L R M S}{ }^{2}=\frac{1}{T_{h}} \int_{0}^{T_{h}} i_{L}^{2}(t) d t
$$

Considering inductor current half-wave symmetry then $i_{L R M S}{ }^{2}$ is achieved from (2) as outlined by (3). Consequently, RMS current can be calculated by substituting the time instants $\left(t_{1}, t_{2}, t_{3}, t_{4}\right)$ from Table I and current instants from Table II into (3).

$i_{L R M S}{ }^{2}\left(K, D_{1}, D_{2}, D_{3}\right)=\frac{1}{3}\left\{i_{L}\left(t_{0}\right)^{2} \cdot\left(t_{1}+1-t_{3}\right)+i_{L}\left(t_{1}\right)^{2} \cdot\left(t_{2}\right)+i_{L}\left(t_{2}\right)^{2} \cdot\left(-t_{1}+\right.\right.$

$\left.t_{3}\right)+i_{L}\left(t_{3}\right)^{2} \cdot\left(-t_{2}+1\right)+i_{L}\left(t_{0}\right) \cdot i_{L}\left(t_{1}\right) \cdot\left(t_{1}\right)+i_{L}\left(t_{1}\right) \cdot i_{L}\left(t_{2}\right) \cdot\left(t_{2}-t_{1}\right)+$

$\left.i_{L}\left(t_{2}\right) \cdot i_{L}\left(t_{3}\right) \cdot\left(t_{3}-t_{2}\right)+i_{L}\left(t_{0}\right) \cdot i_{L}\left(t_{3}\right) \cdot\left(-1+t_{3}\right)\right\}$

\section{Proposed CurRent Stress Minimization Algorithm}

\section{A. Formulation of the Minimization Problem}

In this paper, the minimization objective is the squared RMS inductor current obtained from (3). Mathematical formulation of the proposed multi-constrained minimization problem is given as follows:

\section{Minimize (for given $K$ )}

\section{Subject to}

$$
\text { Obj.Fun. }=i_{L R M S}^{2}\left(K, D_{1}, D_{2}, D_{3}\right)
$$

Equality constraint:

$$
P^{*}=\frac{1}{T_{h}} \int_{0}^{T_{h}} v_{b r 1}(t) \cdot i_{L}(t) d t
$$

And the inequality constraints:

- $0 \leq D_{1} \leq 1,0 \leq D_{2} \leq 1,-1 \leq D_{3} \leq 1$ where $1 \equiv 180^{\circ}$

- Operational constraints of each switching mode (see Table I)

\section{B. Optimization Technique}

Due to its capability to handle multi-constraint optimization problems, particle swarm optimization (PSO) method [29] is chosen to be applied off-line to the DAB model to calculate the optimal phase ratios. PSO imitates the swarm behavior and the individuals represent points (solutions) in the $\mathrm{N}$-dimensional search space. In this case, $N$ is 3 , such that each individual (particle) is composed of a three values $\left(D_{1}, D_{2}\right.$ and $\left.D_{3}\right)$. PSO involves two model equations as outlined by (5) and (6), where $\boldsymbol{X}$ is defined as individual position (solution $\equiv$ TPS ratios) and $\boldsymbol{V}$ is defined as the velocity (deviation) needed to change the individual position $\boldsymbol{X}$ (solution) in each iteration. The velocity of each particle in the $\mathrm{N}$-dimensional space is obtained by (5). The velocity depends on three parameters: the previous velocity, personal experience of the particle and the global experience of the whole swarm. Then each individual's position $\boldsymbol{X}$ in the N-dimensional space is updated using (6) depending on the previous position (solution) and the current velocity.

$$
\begin{gathered}
V_{i}^{m+1}=w V_{i}^{m}+c_{1} r_{1}\left(\mathrm{Pbest}_{i}{ }^{m}-X_{i}{ }^{m}\right)+c_{2} r_{2}\left(\text { Gbest }^{m}-X_{i}{ }^{m}\right) \\
X_{i}{ }^{m+1}=X_{i}^{m}+V_{i}^{m+1}
\end{gathered}
$$

Where

- $m$ is the iteration index, while $c_{1}$ and $c_{2}$ are two positive constants, such that $c_{1}=c_{1}=2$, as the common practice of PSO [29].

- $r_{1}$ and $r_{2}$ are two randomly generated numbers, such that

$$
0 \leq r_{1} \leq 1,0 \leq r_{2} \leq 1
$$

- $w$ is the inertia constant, such that $\mathrm{w}=0.9-(0.005 * m)$.

- Pbest $_{\mathbf{i}}{ }^{\mathbf{m}}$ is the best position particle based on its own experience

- $\mathbf{G b e s t}^{\boldsymbol{m}}$ is the best position based on overall swarm's experience.

The flowchart of the PSO algorithm is presented in Fig. 4. Before executing the iterations, a vector of particle positions $\boldsymbol{X}$ is randomly generated (random TPS solutions). In each iteration the following steps are carried out:

- Each particle $\boldsymbol{X}_{\boldsymbol{i}}{ }^{\boldsymbol{m}}$ is evaluated at iteration $\boldsymbol{m}$. The outputs of this evaluation are (power transfer evaluated at $\boldsymbol{X}_{\boldsymbol{i}}{ }^{\boldsymbol{m}}$ ) and (Obj.Fun. evaluated at $\boldsymbol{X}_{\boldsymbol{i}}{ }^{\boldsymbol{m}}$ ).

- The evaluation of (Obj.Fun. at $\left.\boldsymbol{X}_{\boldsymbol{i}}{ }^{\boldsymbol{m}}\right)$ i.e. $\left(i_{L R M S}{ }^{2}\right)$ for individual $\boldsymbol{X}_{\boldsymbol{i}}{ }^{\boldsymbol{m}}$ is compared to the evaluation of the same individual from the previous iteration; hence the particle position $\boldsymbol{X}_{\boldsymbol{i}}{ }^{\boldsymbol{m}}$ achieving the minimum evaluation value is defined as personal best value $\mathbf{P b e s t}_{\mathbf{i}}{ }^{\mathbf{m}}$.

- The previous comparison is done with respect to the equality constraint defined in section III-A.

- Then the Pbest achieving the minimum $I_{L R M S}{ }^{2}$ value between all particles (the entire swarm) is identified as the global best value Gbest.

- Then using (5) and (6), the velocity and position of individuals are updated respectively with respect to the inequality constraints defined in section III-A.

The previous steps are carried out for all the possible switching modes according to the reference power $\boldsymbol{P} *$. After all iteration are executed, the Gbest is identified which includes the optimal TPS ratios hence minimum $I_{L R M S}{ }^{2}$ is obtained with accompanied switching mode.

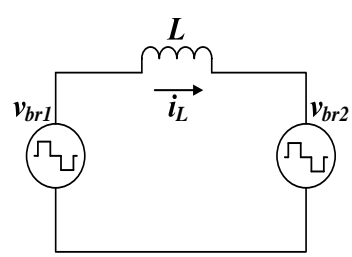

Fig. 3. DAB equivalent circuit.

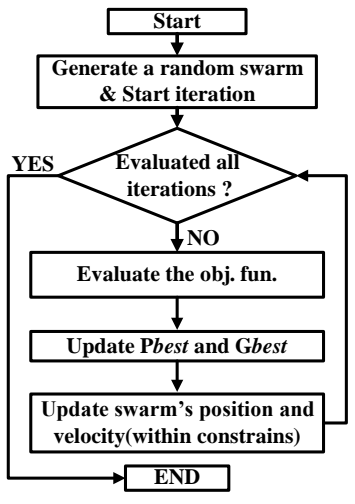

Fig. 4. Flow chart of PSO. 
TABLE I

DAB MODES OF OPERATION \& PER UNIT POWER EQUATIONS USING TPS CONTROL

\begin{tabular}{|c|c|c|c|c|}
\hline & Mode 1 & Mode 1' & Mode 2 & Mode 2' \\
\hline Waveforms & $t_{t_{0} t_{1}} t_{t_{2}} t_{t_{3}}^{D_{t_{3}} t_{h}}$ & $\stackrel{D_{b r 1}}{D_{2} T_{h}}$ & $\underset{L_{L}}{\stackrel{D_{2} T_{h}}{\longrightarrow}}$ & $\underset{t_{3}}{v_{t_{4}} v_{t_{5}}}$ \\
\hline $\begin{array}{l}\text { Normalized } \\
\text { time instants } \\
\quad \text { to } T_{h}\end{array}$ & $\begin{aligned} t_{0}=0, t_{1} & =D_{3}, t_{2}=D_{2}+D_{3} \\
t_{3} & =D_{1}, t_{4}=1\end{aligned}$ & $\begin{array}{c}t_{0}=0, t_{1}=D_{3}+1, t_{2}=D_{2}+D_{3}+1 \\
t_{3}=D_{1}, t_{4}=1\end{array}$ & $\begin{array}{c}t_{0}=0, t_{1}=D_{1}, t_{2}=D_{2}+D_{3}-1 \\
t_{3}=D_{3}, t_{4}=1\end{array}$ & $\begin{array}{c}t_{0}=0, t_{1}=D_{1}, t_{2}=D_{2}+D_{3} \\
t_{3}=D_{3}+1, t_{4}=1\end{array}$ \\
\hline $\begin{array}{l}\text { Operational } \\
\text { Constraints }\end{array}$ & $\begin{aligned} D_{1} & \geq D_{2} \\
0 \leq D_{3} & \leq D_{1}-D_{2}\end{aligned}$ & $\begin{array}{c}D_{1} \geq D_{2} \\
0 \leq D_{3}+1 \leq D_{1}-D_{2}\end{array}$ & $\begin{array}{c}D_{2} \geq D_{1} \\
\left(1+D_{1}-D_{2}\right) \leq D_{3} \leq 1\end{array}$ & $\begin{array}{c}D_{2} \geq D_{1} \\
\left(1+D_{1}-D_{2}\right) \leq D_{3}+1 \leq 1\end{array}$ \\
\hline $\begin{array}{c}\text { Power } \\
\text { Transfer }\end{array}$ & $P=2 K\left(D_{2}^{2}-D_{1} D_{2}+2 D_{2} D_{3}\right)$ & $P=-2 K\left(D_{2}^{2}-D_{1} D_{2}+2 D_{2}\left(D_{3}+1\right)\right)$ & $P=2 K\left(D_{1}^{2}-D_{1} D_{2}+2 D_{1}-2 D_{1} D_{3}\right)$ & $P=-2 K\left(D_{1}^{2}-D_{1} D_{2}-2 D_{1} D_{3}\right)$ \\
\hline $\begin{array}{l}\text { Power } \\
\text { Range }\end{array}$ & $\begin{array}{c}P_{\max }=0.5 \mathrm{~K} p u, P_{\min }=-0.5 \mathrm{~K} p u \\
\text { Mode } 3 \\
\end{array}$ & $\begin{array}{c}P_{\max }=0.5 \mathrm{~K} p u, P_{\min }=-0.5 \mathrm{~K} p u \\
\text { Mode 3' }\end{array}$ & $\begin{array}{c}P_{\max }=0.5 \mathrm{~K} p u, P_{\min }=-0.5 \mathrm{~K} p u \\
\text { Mode } 4 \\
\end{array}$ & $\begin{array}{c}P_{\max }=0.5 \mathrm{~K} p u, P_{\min }=-0.5 \mathrm{~K} p u \\
\text { Mode 4' }\end{array}$ \\
\hline Waveforms & $\stackrel{D_{3} T_{h}}{\stackrel{D_{1} T_{h}}{\longrightarrow}}$ & 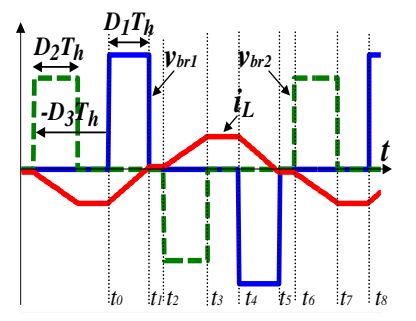 & 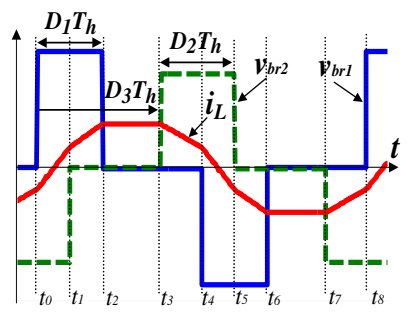 & $\stackrel{D_{1} T_{h}}{\stackrel{\longrightarrow}{:}}$ \\
\hline $\begin{array}{l}\text { Normalized } \\
\text { time instants } \\
\quad \text { to } T_{h}\end{array}$ & $\begin{array}{c}t_{0}=0, t_{1}=D_{1}, t_{2}=D_{3} \\
t_{3}=D_{2}+D_{3}, t_{4}=1\end{array}$ & $\begin{array}{c}t_{0}=0, t_{1}=D_{1}, t_{2}=D_{3}+1 \\
t_{3}=D_{2}+D_{3}+1, t_{4}=1\end{array}$ & $\begin{array}{c}t_{0}=0, t_{1}=D_{2}+D_{3}-1, t_{2}=D_{1} \\
t_{3}=D_{3}, t_{4}=1\end{array}$ & $\begin{array}{c}t_{0}=0, t_{1}=D_{2}+D_{3}, t_{2}=D_{1} \\
t_{3}=D_{3}+1, t_{4}=1\end{array}$ \\
\hline $\begin{array}{l}\text { Operational } \\
\text { Constraints }\end{array}$ & $\begin{array}{c}D_{2} \leq 1-D_{1} \\
D_{1} \leq D_{3} \leq 1-D_{2}\end{array}$ & $\begin{array}{c}D_{2} \leq 1-D_{1} \\
D_{1} \leq D_{3}+1 \leq 1-D_{2}\end{array}$ & $\begin{array}{c}D_{1} \leq D_{3} \leq 1 \\
1-D_{3} \leq D_{2} \leq 1-D_{3}+D_{1}\end{array}$ & $\begin{array}{c}D_{1} \leq D_{3}+1 \leq 1 \\
-D_{3} \leq D_{2} \leq-D_{3}+D_{1}\end{array}$ \\
\hline $\begin{array}{c}\text { Power } \\
\text { Transfer }\end{array}$ & $P=2 K\left(D_{1} D_{2}\right)$ & $P=-2 K\left(D_{1} D_{2}\right)$ & $\begin{array}{c}P=2 K\left(-D_{2}^{2}-D_{3}^{2}+2 D_{2}+2 D_{3}\right. \\
\left.-2 D_{2} D_{3}+D_{1} D_{2}-1\right)\end{array}$ & $\begin{array}{l}P=-2 K\left(-D_{2}{ }^{2}-\left(D_{3}+1\right)^{2}\right. \\
\left.+2 D_{3}-2 D_{2} D_{3}+D_{1} D_{2}+1\right)\end{array}$ \\
\hline $\begin{array}{l}\text { Power } \\
\text { Range }\end{array}$ & $\begin{array}{c}P_{\max }=0.5 \mathrm{~K} p u, P_{\min }=0.0 \mathrm{pu} \\
\text { Mode } 5\end{array}$ & $\begin{array}{c}P_{\max }=0.0 p u, P_{\min }=-0.5 \mathrm{Kpu} \\
\text { Mode 5' }\end{array}$ & $\begin{array}{c}P_{\max }=0.667 \mathrm{Kpu}, P_{\min }=0.0 \mathrm{pu} \\
\text { Mode 6 }\end{array}$ & $\begin{array}{c}P_{\max }=0.0 \mathrm{pu}, P_{\min }=-0.667 \mathrm{~K} p u \\
\text { Mode 6' }\end{array}$ \\
\hline Waveforms & to $t_{1} t_{2}$ & to & 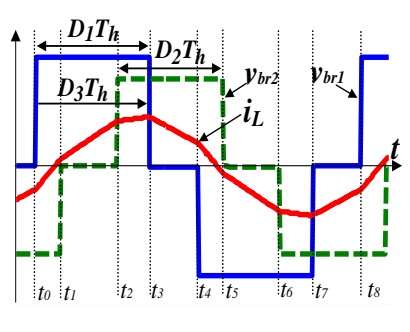 & (t) \\
\hline $\begin{array}{l}\text { Normalized } \\
\text { time instants } \\
\text { to } T_{h} \\
\end{array}$ & $\begin{array}{c}t_{0}=0, t_{1}=D_{3}, t_{2}=D_{1} \\
t_{3}=D_{2}+D_{3}, t_{4}=1\end{array}$ & $\begin{array}{c}t_{0}=0, t_{1}=D_{3}+1, t_{2}=D_{1} \\
t_{3}=D_{2}+D_{3}+1, t_{4}=1\end{array}$ & $\begin{array}{c}t_{0}=0, t_{1}=D_{2}+D_{3}-1, t_{2}=D_{3} \\
t_{3}=D_{1}, t_{4}=1\end{array}$ & $\begin{array}{c}t_{0}=0, t_{1}=D_{2}+D_{3}, t_{2}=D_{3}+1 \\
t_{3}=D_{1}, t_{4}=1\end{array}$ \\
\hline $\begin{array}{l}\text { Operational } \\
\text { Constraints }\end{array}$ & $\begin{array}{c}D_{1}-D_{3} \leq D_{2} \leq 1-D_{3} \\
0 \leq D_{3} \leq D_{1}\end{array}$ & $\begin{array}{c}D_{1}-D_{3}-1 \leq D_{2} \leq-D_{3} \\
0 \leq D_{3}+1 \leq D_{1}\end{array}$ & $\begin{array}{c}1-D_{2} \leq D_{1} \\
1-D_{2} \leq D_{3} \leq D_{1}\end{array}$ & $\begin{array}{c}1-D_{2} \leq D_{1} \\
1-D_{2} \leq D_{3}+1 \leq D_{1}\end{array}$ \\
\hline $\begin{array}{c}\text { Power } \\
\text { Transfer }\end{array}$ & $\begin{array}{c}P=2 K\left(-D_{1}^{2}-D_{3}^{2}+D_{1} D_{2}\right. \\
\left.+2 D_{1} D_{3}\right)\end{array}$ & $\begin{aligned} P & =-2 K\left(-D_{1}^{2}-\left(D_{3}+1\right)^{2}\right. \\
& \left.+D_{1} D_{2}+2 D_{1}\left(D_{3}+1\right)\right)\end{aligned}$ & $\begin{array}{c}P=2 K\left(-D_{1}{ }^{2}-D_{2}{ }^{2}-2 D_{3}{ }^{2}+2 D_{3}\right. \\
\left.-2 D_{2} D_{3}+D_{1} D_{2}+2 D_{1} D_{3}+2 D_{2}-1\right)\end{array}$ & $\begin{array}{c}P=-2 K\left(-D_{1}^{2}-D_{2}{ }^{2}-2\left(D_{3}+1\right)^{2}\right. \\
+2 D_{3}-2 D_{2} D_{3}+D_{1} D_{2} \\
\left.+2 D_{1}\left(D_{3}+1\right)+1\right)\end{array}$ \\
\hline $\begin{array}{l}\text { Power } \\
\text { Range }\end{array}$ & $P_{\max }=0.667 \mathrm{Kpu}, P_{\min }=0.0 \mathrm{pu}$ & $P_{\max }=0.0 \mathrm{pu}, P_{\min }=-0.667 \mathrm{~K} p u$ & $P_{\max }=K \quad p u, P_{\min }=0.0 p u$ & $P_{\max }=0.0 p u, P_{\min }=-K p u$ \\
\hline
\end{tabular}


TABLE II

PER UNIT INDUCTOR CURRENTS $\left(I_{L}\right)$ FOR POSITIVE HALF CYCLE SWITCHING INTERVALS NORMALIZED TO $\mathrm{I}_{\mathrm{BASE}}$

\begin{tabular}{|c|c|c|c|c|}
\hline Modes & $i_{L}\left(t_{0}\right)$ & $i_{L}\left(t_{I}\right)$ & $i_{L}\left(t_{2}\right)$ & $i_{L}\left(t_{3}\right)$ \\
\hline 1 & $-\left(D_{1}-K D_{2}\right)$ & $\left(-D_{1}+2 D_{3}+K D_{2}\right)$ & $\left(-D_{1}+2 D_{2}+2 D_{3}-K D_{2}\right)$ & $\left(D_{1}-K D_{2}\right)$ \\
\hline 1' & $-\left(D_{1}+K D_{2}\right)$ & $\left(-D_{1}+2\left(D_{3}+1\right)-K D_{2}\right)$ & $\left(-D_{1}+2 D_{2}+2\left(D_{3}+1\right)+K D_{2}\right)$ & $\left(D_{1}+K D_{2}\right)$ \\
\hline 2 & $-\left(D_{1}-2 K+K D_{2}+2 K D_{3}\right)$ & $\left(D_{1}+2 K D_{1}-K D_{2}+2 K-2 K D_{3}\right)$ & $\left(D_{1}+K D_{2}\right)$ & $\left(D_{1}+K D_{2}\right)$ \\
\hline 2' & $-\left(D_{1}+2 K-K D_{2}-2 K\left(D_{3}+1\right)\right)$ & $\left(D_{1}-2 K-2 K D_{1}+K D_{2}+2 K\left(D_{3}+1\right)\right)$ & $\left(D_{1}-K D_{2}\right)$ & $\left(D_{1}-K D_{2}\right)$ \\
\hline 3 & $-\left(D_{1}-K D_{2}\right)$ & $\left(D_{1}+K D_{2}\right)$ & $\left(D_{1}+K D_{2}\right)$ & $\left(D_{1}-K D_{2}\right)$ \\
\hline 3 & $-\left(D_{1}+K D_{2}\right)$ & $\left(D_{1}-K D_{2}\right)$ & $\left(D_{1}-K D_{2}\right)$ & $\left(D_{1}+K D_{2}\right)$ \\
\hline 4 & $-\left(D_{1}-2 K+K D_{2}+2 K D_{3}\right)$ & $\left(-D_{1}-2+2 D_{2}+K D_{2}+2 D_{3}\right)$ & $\left(D_{1}+K D_{2}\right)$ & $\left(D_{1}+K D_{2}\right)$ \\
\hline 4 & $-\left(D_{1}+2 K-K D_{2}-2 K\left(D_{3}+1\right)\right)$ & $\left(-D_{1}-2+2 D_{2}+2\left(D_{3}+1\right)-K D_{2}\right)$ & $\left(D_{1}-K D_{2}\right)$ & $\left(D_{1}-K D_{2}\right)$ \\
\hline 5 & $-\left(D_{1}-K D_{2}\right)$ & $\left(-D_{1}+2 D_{3}+K D_{2}\right)$ & $\left(D_{1}-2 K D_{1}+K D_{2}+2 K D_{3}\right)$ & $\left(D_{1}-K D_{2}\right)$ \\
\hline 5' & $-\left(D_{1}+K D_{2}\right)$ & $\left(-D_{1}+2\left(D_{3}+1\right)-K D_{2}\right)$ & $\left(D_{1}+2 K D_{1}-K D_{2}-2 K\left(D_{3}+1\right)\right)$ & $\left(D_{1}+K D_{2}\right)$ \\
\hline 6 & $-\left(D_{1}+K D_{2}+2 K D_{3}-2 K\right)$ & $\left(-D_{1}+2 D_{2}+2 D_{3}+K D_{2}-2\right)$ & $\left(-D_{1}+2 D_{3}+K D_{2}\right)$ & $\left(D_{1}-2 K D_{1}+K D_{2}+2 K D_{3}\right)$ \\
\hline 6' & $-\left(D_{1}-K D_{2}-2 K\left(D_{3}+1\right)+2 K\right)$ & $\left(-D_{1}+2 D_{2}+2\left(D_{3}+1\right)-K D_{2}-2\right)$ & $\left(-D_{1}+2\left(D_{3}+1\right)-K D_{2}\right)$ & $\left(D_{1}+2 K D_{1}-K D_{2}-2 K\left(D_{3}+1\right)\right)$ \\
\hline
\end{tabular}

\section{PSO OFF-LINE ALGORITHM ANALYSIS}

The off-line optimal phase shift calculations were carried out using MATLAB software, based on the proposed per unit DAB equations and constraints. Assuming that $K=V_{d c 2} / V_{d c l}$ and $K \leq 1$, the other condition $K>1$ can be analyzed similarly. The buck/boost mode is included in this paper as bi-directional power at $K<1$ inherently includes buck mode for operation in forward power flow and boost mode for operation in reverse power flow. The values of voltage conversion ratio $(K)$ used in this section were:

- $K=0.25,0.4$ and 0.6 representing buck/boost mode.

- $K=1$ representing unity gain operating mode.

The optimal solutions of the three phase ratios are presented in Fig. 5 parts (a) to (c) and Fig. 6 where the full per unit power range is from $-K$ to $K$; such that $\left|P_{\text {max }-p u}\right|=K$. This is calculated by normalizing the DAB maximum power transfer from (7) to the base power expressed in (8). The PSO is applied in the entire power range for both power flow directions; such that positive power transfer indicates power flow from bridge 1 to bridge 2 and vice versa. A general pattern for the optimal phase shifts ratios in buck/boost mode is developed in Fig. 5 (d) where the entire power range is divided into four sections.

$$
\begin{gathered}
P_{\text {max }}=\frac{V_{d c 1} V_{d c 2}}{8 f_{s} L}, \text { Where } V_{d c 2}=K V_{d c 1} \\
P_{\text {base }}=\frac{V_{\text {base }}{ }^{2}}{Z_{\text {base }}}=\frac{V_{d c 1}{ }^{2}}{8 f_{s} L}
\end{gathered}
$$

Regarding the optimal solutions in buck/boost mode shown in Fig. 5 parts (a) to (c):

- If desired power $\left|\boldsymbol{P}^{*}\right| \leq \mathbf{0 . 5 K}$, optimal solutions were attained by (TPS) where minimum $i_{L R M S}$ is achieved by the switching modes 2' as shown in Fig. 5 (d).

- If desired power $\left|\boldsymbol{P}^{*}\right| \geq \mathbf{0 . 5} \boldsymbol{K}$, extended phase shift (EPS) [16] and conventional phase shift (CPS) achieved the optimal solution, as shown in Fig. 5 (d), where the minimum $i_{L R M S}$ is realized by switching modes 6 and 6 ' for positive and negative power transfer respectively.

On the other hand, Fig. 6 shows that the conventional phase shift (CPS) [1] fulfills optimal solutions for unity gain operating mode at the entire loading range at both power flow directions. In this special case, the optimal solutions were attained by mode 6 or mode 6' with $D_{l}=D_{2}=1$.

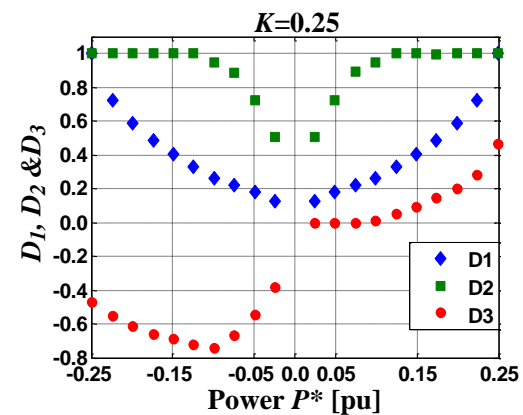

(a)

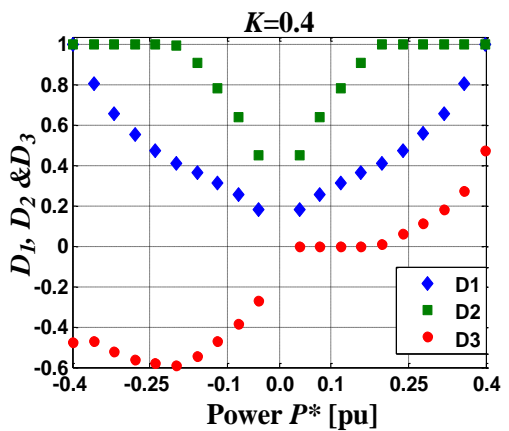

(b)

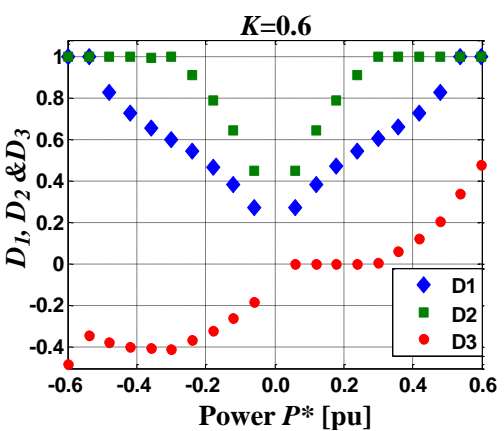

(c)

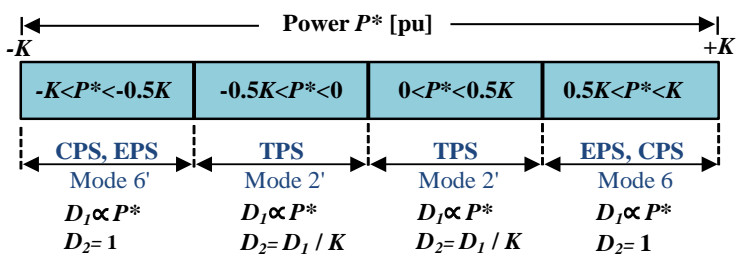

(d)

Fig. 5. Application of PSO to the DAB for buck/boost mode: (a)-(c) Optimal phase shift ratios at $K=0.25,0.4$ and 0.6 respectively (d) General pattern of optimal TPS at buck/boost mode. 


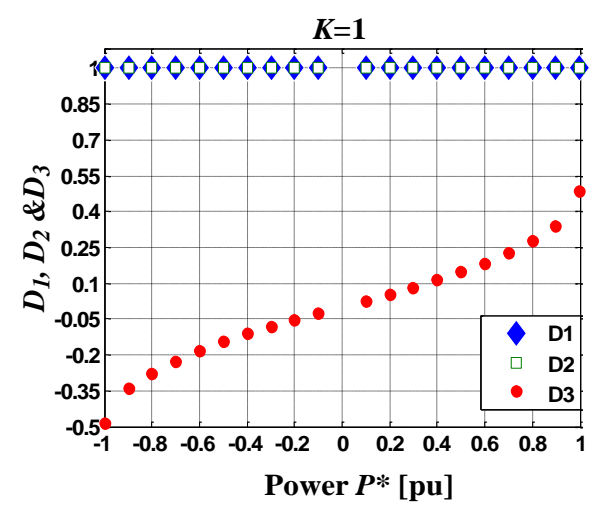

Fig. 6. Optimal phase shift ratios unity gain mode $K=1$.

\section{Closed LoOp CONTROL DESIGN}

The extensive set of optimal TPS ratios, presented in previous section, presents a generic data pool. This data is carefully analyzed to derive simple relations which are used to design the generalized closed loop control scheme presented in Fig. 7.

In buck/boost mode, $D_{l}$ can be regulated through a PI controller as the relation between power and $D_{l}$ is almost linear throughout which can be noticed in Fig. 5 parts (a) to (c). Whereas the relationship between the other control parameters $\left(D_{2}\right.$ and $\left.D_{3}\right)$ and power is non-linear and dependent on the power level.

The following relations can be concluded from Fig. 5 parts (a) to $(\mathrm{c})$ :

- For $\left|P^{*}\right| \geq 0.5 K$ : optimal value of $D_{2}$ is $\left(D_{2}=1\right)$. The value of $D_{3}$ is highly non-linear and therefore can only be calculated from re-arranging mode 6 and mode 6 ' power equations in Table I. For forward power flow this is shown in (9.a), and for reverse power flow this is shown in (9.b).

- $\boldsymbol{F o r}\left|\boldsymbol{P}^{*}\right|<\mathbf{0 . 5 K}$ : optimal value of $D_{2}$ is $D_{2}=D_{1} / K$. The value of $D_{3}$ is highly non-linear and therefore can only be calculated from re-arranging mode 2' power equation in Table I. The calculation of $D_{3}$ in this section is shown in (9.c) for both forward and reverse power flow.

$$
D_{3}=\left\{\begin{array}{l}
\frac{\frac{-\left(-1+D_{2}-D_{1}\right)-\sqrt{2 D_{1}+2 D_{2}-D_{1}{ }^{2}-D_{2}{ }^{2}-\frac{P^{*}}{K}-1}}{2}, \text { for } P^{*} \geq 0.5 K}{\frac{-\left(1+D_{2}-D_{1}\right)+\sqrt{2 D_{1}+2 D_{2}-D_{1}{ }^{2}-D_{2}{ }^{2}+\frac{P^{*}}{K}-1}}{2}, \text { for } P^{*} \leq-0.5 K} \\
0.5\left(D_{1}-D_{2}+\frac{P^{*}}{2 K D_{1}}\right), \quad \text { for }-0.5 K<P^{*}<0.5 K
\end{array}\right.
$$

In unity gain mode, Fig. 6 shows that both $\mathrm{DAB}$ bridge $\mathrm{AC}$ voltages are full square waves $\left(D_{l}=D_{2}=1\right)$ for the entire bidirectional power range and the only control needed to regulate power flow is on $D_{3}$. This can be implemented using a PI controller because the relation between the power level and value of the third phase shift $D_{3}$ is almost linear as depicted in Fig. 6.

The close-loop variable is the sending end power $\left(P_{s e}\right)$ such that $P_{s e}=P_{b r 1}$ for positive power flow while $P_{s e}=P_{b r 2}$ for negative power flow, where $P_{b r 1}$ and $P_{b r 2}$ are the H-bridge powers measured at the DC sides of bridges 1 and 2 respectively.

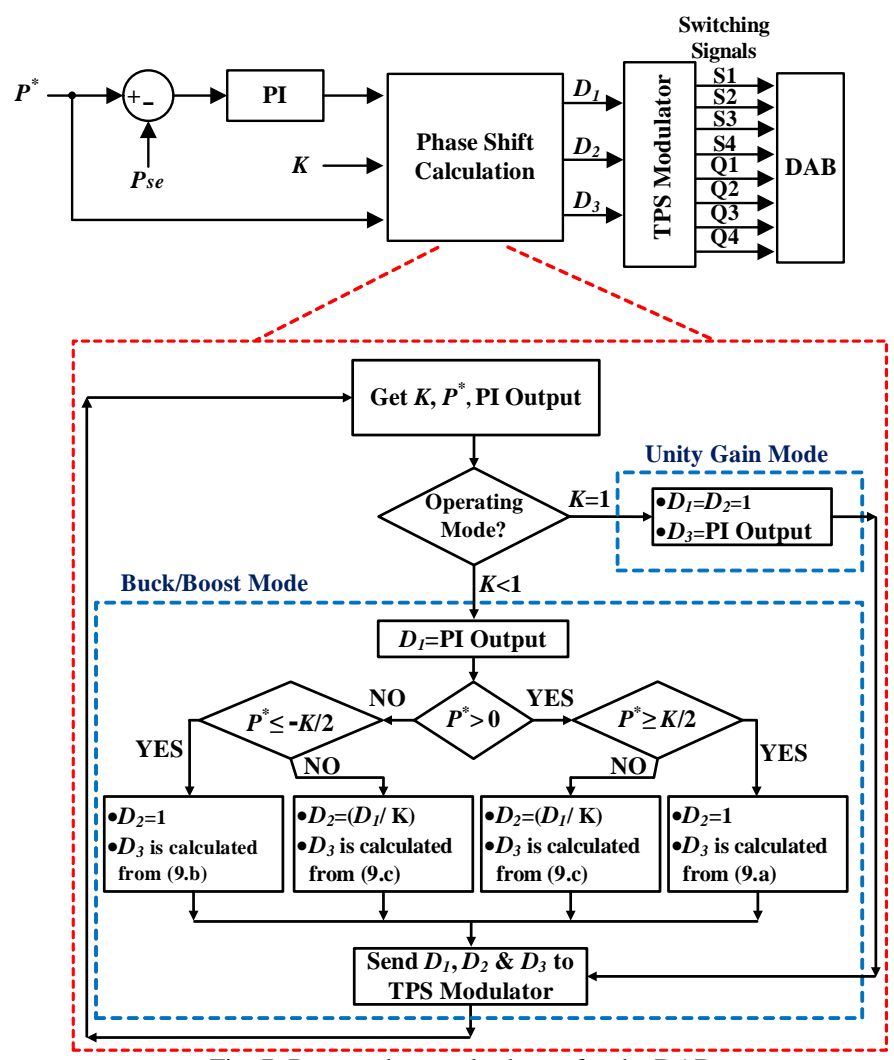

Fig. 7. Proposed control scheme for the DAB.

\section{SIMULATION RESULTS}

To confirm the presented analysis, detailed simulations using SIMULINK/MATLAB platform software were performed. The simulations were carried out for the buck/boost/unity operating modes using the DAB parameters described in Table III.

TABLE III

PARAMETERS OF THE EXPERIMENTAL SETUP

\begin{tabular}{|l|l|}
\hline \multicolumn{1}{|c|}{ Parameter } & value \\
\hline Bridge 1 DC Voltage $V_{d c l}$ & $100 \mathrm{~V}$ \\
\hline Bridge 2 DC Voltage $V_{d c 2}$ & $K^{*} 100 \mathrm{~V}$ \\
\hline Switching Frequency $f_{s}$ & $2.5 \mathrm{kHz}$ \\
\hline Base Power $P_{\text {base }}$ & $500 \mathrm{~W}$ \\
\hline Interface inductor $L$ & $1 \mathrm{mH}$ \\
\hline
\end{tabular}

\section{A. Effectiveness of the proposed control scheme}

The effectiveness of the proposed control algorithm to track reference power level while maintaining minimum current stresses is verified in this section by applying bidirectional step changes of reference power level at various voltage conversion ratios. The results are presented in Fig. 8, where the sending end power is measured and plotted against the reference power level. In addition, associated measured RMS inductor current ( $i_{L \text { act }}$ ) is shown along with the minimum possible RMS inductor current $\left(i_{L \text { min }}\right)$ calculated offline by the PSO. It can be noticed that the proposed power flow controller is capable of tracking the bidirectional reference power level at different voltage conversion ratios. Moreover $\left(i_{L a c t}\right)$ is maintained very close to $\left(i_{L \text { min }}\right)$ which confirms minimum losses. 


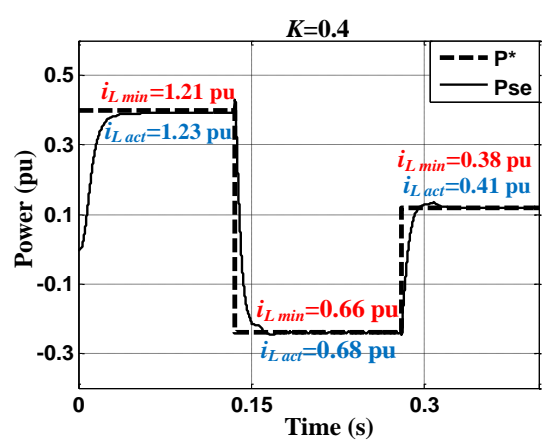

(a)

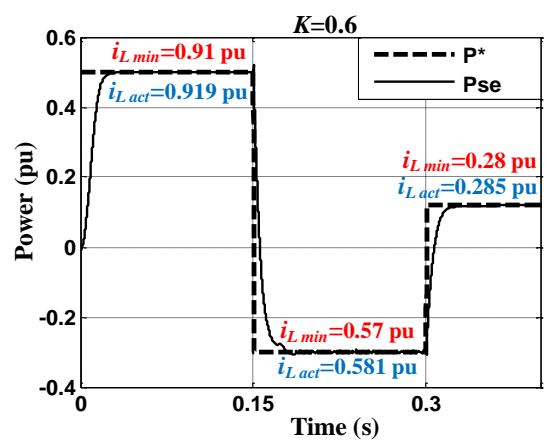

(b)

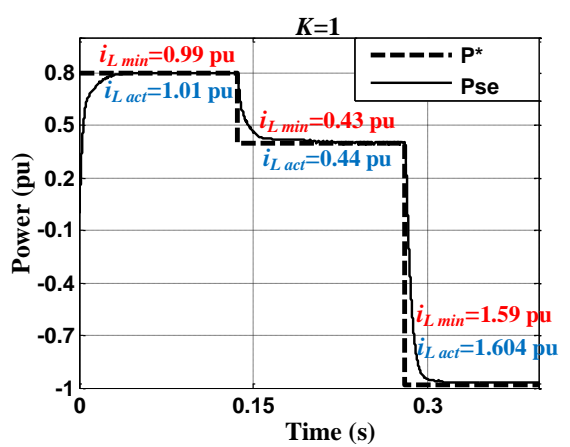

(c)

Fig. 8: Response of power transfer with current stresses at different power levels for different voltage conversion ratios: (a) $K=0.4$ (b) $K=0.6$ (c) $K=1$.

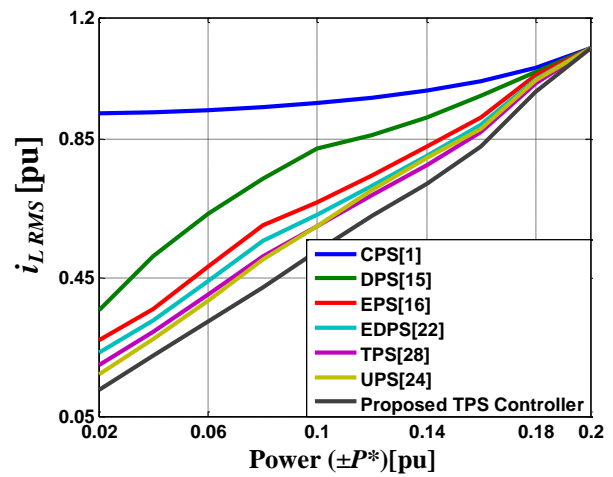

(a)

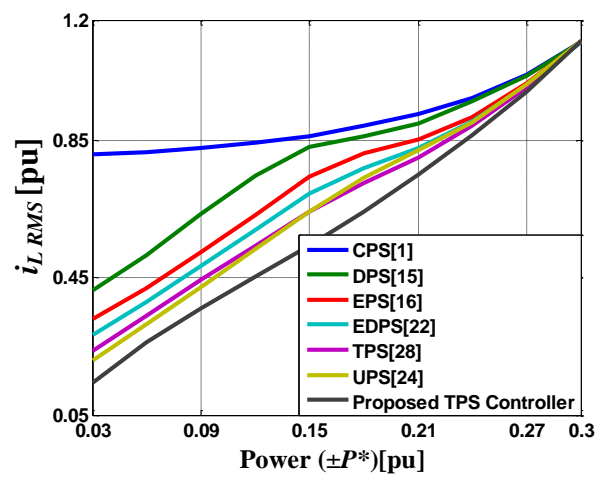

(b)

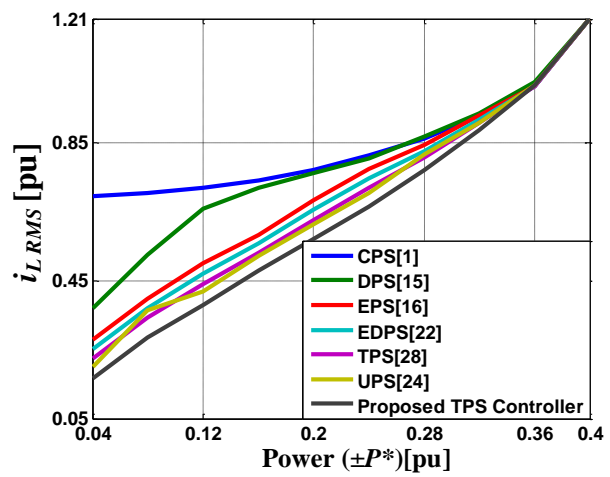

(c)

Fig. 9: Curves of current stress $i_{L R M S}$ with respect to $P^{*}$ and $K$ in CPS[1], DPS[15], EPS[16], EDPS[22], TPS[28], UPS[24] and proposed TPS controller at: (a) $K=0.2$, (b) $K=0.3$, (c) $K=0.4$.

\section{B. Comparative analysis with other phase shift methods}

A comprehensive comparison between the proposed phase shift technique and other phase shift techniques in literature is provided in this section. The phase shift techniques to compare the proposed phase shift technique with are: Conventional phase shift (CPS) [1], Dual phase shift (DPS) [15], Extended phase shift (EPS) [16], Extended dual phase shift (EDPS) [22], Triple phase shift [28] and Unified phase shift [24]. The entire per unit bi-directional power range ( $-K$ pu to $K \mathrm{pu}$ ) is considered in all techniques. The RMS inductor current is compared for all mentioned techniques at different voltage conversion ratios $K$ as shown in Fig.9. The current is the main factor affecting the efficiency; hence it is displayed first where the proposed phase shift technique is achieving the lowest current stresses.

Moreover, efficiency calculations, outlined by (10), have been carried out in simulations at the DC side to include switching and copper losses. The DAB circuit diagram shown in Fig.1 is used in the simulation where the variables used for efficiency calculation $\left(V_{d c}, I_{d c}, V_{d c 2}, I_{d c 2}\right)$ are shown along with the parasitic resistance (AC link) resistance $\left(R_{a c}\right)$. The values for this resistance is chosen carefully to produce reliable results such that $R_{a c}=0.06 \mathrm{pu}$, where $Z_{\text {base }}=8 f_{s w} L$. The efficiency curves, presented in Fig.10, show that the proposed method achieves better performance than other existing phase shift schemes.

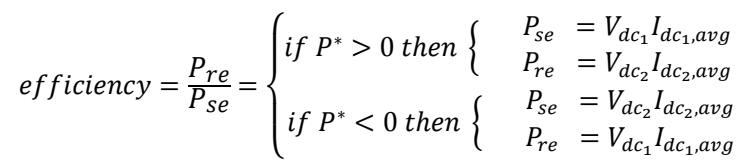

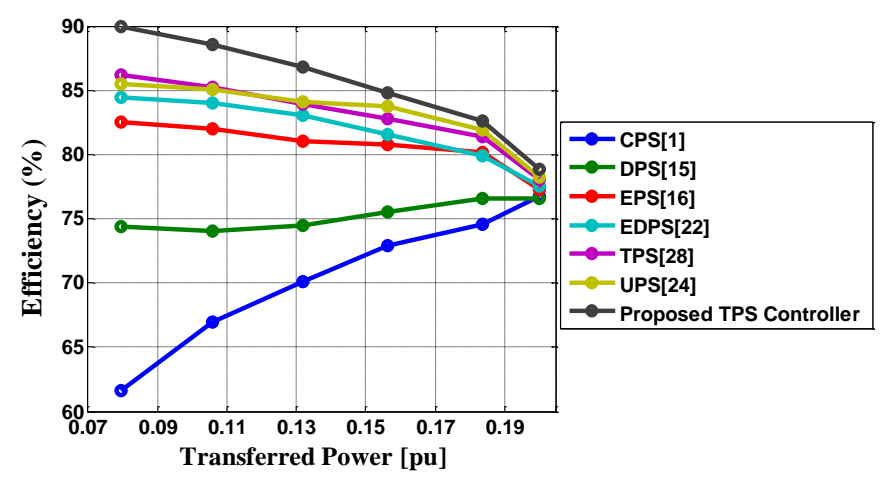

(a)

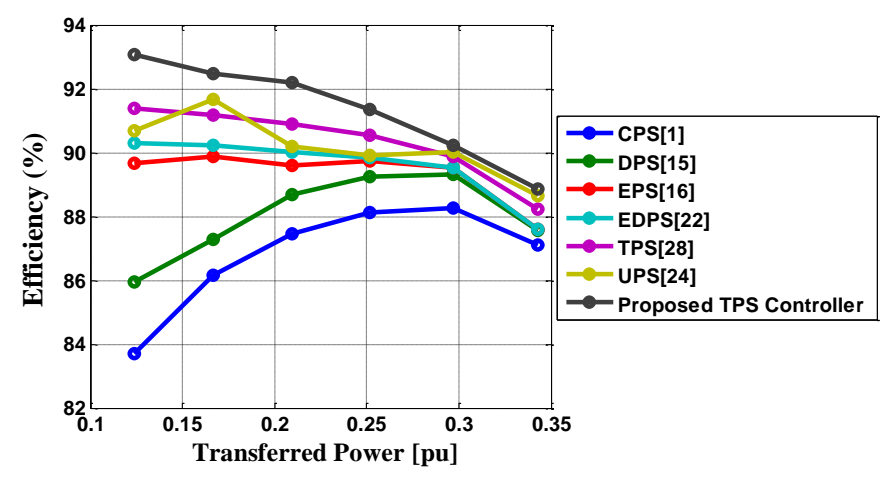

(b)

Fig.10. Efficiency curves using existing phase shift techniques and the proposed TPS controller: (a) $K=0.2$, (b) $K=0.4$ 


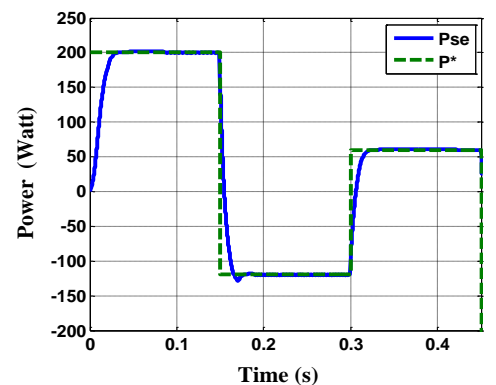

(a)

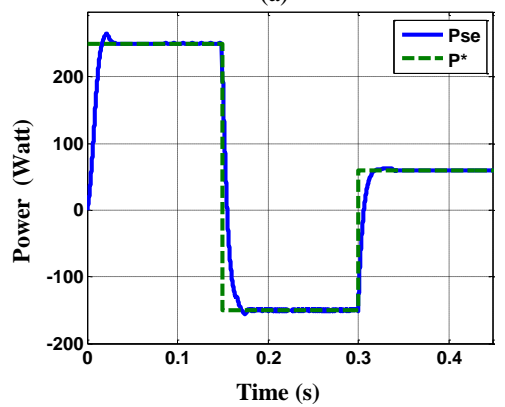

(d)

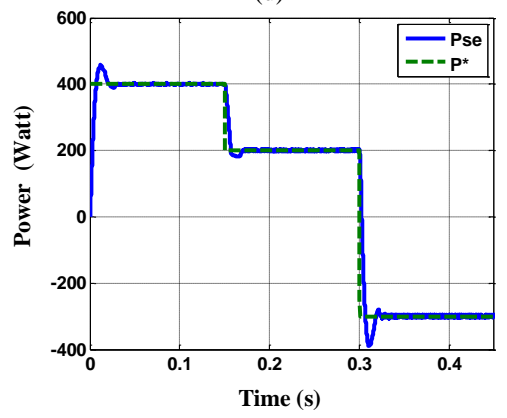

(g)

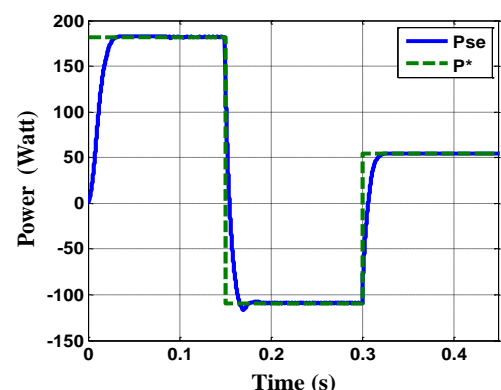

(b)

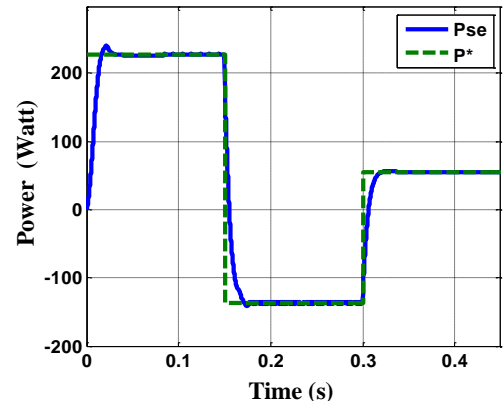

(e)

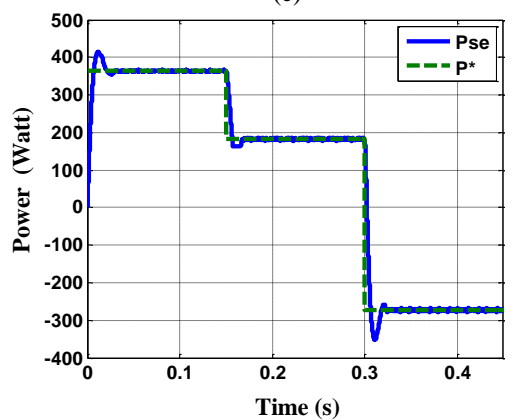

(h)

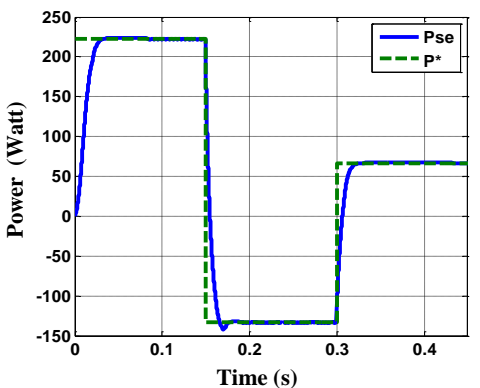

(c)

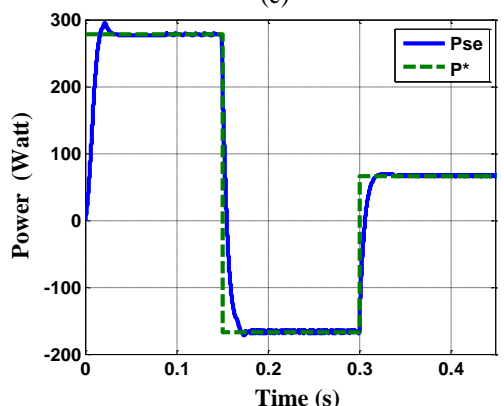

(f)

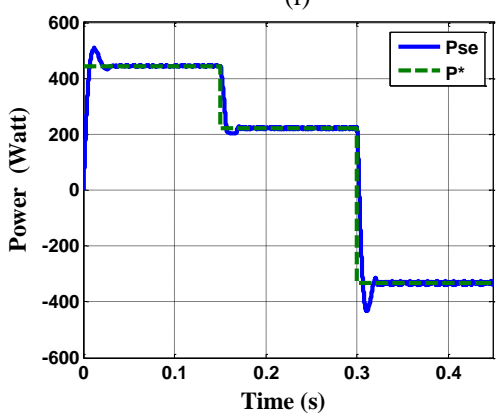

(i)

Fig. 11. Robustness of the proposed control algorithm to different system conditions (a) $K=0.4, L=1 \mathrm{mH}, R_{a c}=1.2 \Omega$, (b) $K=0.4, L=1 \mathrm{mH}+10 \%, R_{a c}=1.2 \Omega+10 \%$, (c) $K=0.4, L=1 \mathrm{mH}-10 \%, R_{a c}=1.2 \Omega-10 \%$, (d) $K=0.6, L=1 \mathrm{mH}, R_{a c}=1.2 \Omega$, (e) $K=0.6, L=1 \mathrm{mH}+10 \%, R_{a c}=1.2 \Omega+10 \%$, (f) $K=0.6, L=1 \mathrm{mH}-10 \%, R_{a c}=1.2 \Omega-10 \%$, (g) $K=1.0, L=1 \mathrm{mH}, R_{a c}=1.2 \Omega$, (h) $K=1.0, L=1 \mathrm{mH}+10 \%, R_{\mathrm{ac}}=1.2 \Omega+10 \%$, (i) $K=1.0, L=1 \mathrm{mH}-10 \%, R_{\mathrm{ac}}=1.2 \Omega-10 \%$.

\section{Robustness of the proposed control scheme}

In order to test proposed controller robustness, simulations have been implemented with values of inductor and its parasitic resistance ( $L$ and $R_{a c}$ respectively) changing by $\pm 10 \%$. The proposed controller is applied on the DAB circuit for three cases: $\left(L=1 \mathrm{mH}, R_{a c}=1.2 \Omega, P_{\text {rated }}=500 \mathrm{Watt}\right),\left(L=1 \mathrm{mH}+10 \%, R_{a c}\right.$ $\left.=1.2 \Omega+10 \%, P_{\text {rated }}=454.5 \mathrm{Watt}\right)$ and $\left(L=1 \mathrm{mH}-10 \%, R_{a c}=1.2 \Omega-10 \%\right.$ , $\left.P_{\text {rated }}=555.5 \mathrm{Watt}\right)$. The proposed controller response in terms of sending end power $P_{s e}$ plotted against ref. power $P^{*}$ for the three cases listed above are shown in Fig. 11. The simulation is carried out at three different voltage conversion ratios $K$ for each of the three cases of parameter variation described. The DAB response while parameters change show that the control algorithm is stable and robust and can be applied to any DAB converter regardless of rating and parameters. This is because the proposed analysis is all per unit and generically standardized.

\section{EXPERIMENTAL RESULTS}

A low scaled experimental DAB setup was developed according the schematic shown in Fig. 12 in order to validate the proposed closed loop controller. The parameters used for designing the test rig are listed in Table III. The entire analysis in the paper is based on transformer-less DAB, as the main scope is the derivation and implementation of new controller. The DAB is based, in theory and experiment, on an AC inductor which is fundamentally the equivalent model of a transformer's leakage inductance. Based on this, a $1 \mathrm{mH}$ air core inductance is employed in the experimental rig while the semiconductor switches used are MOSFETs (MOSFET IRF250).

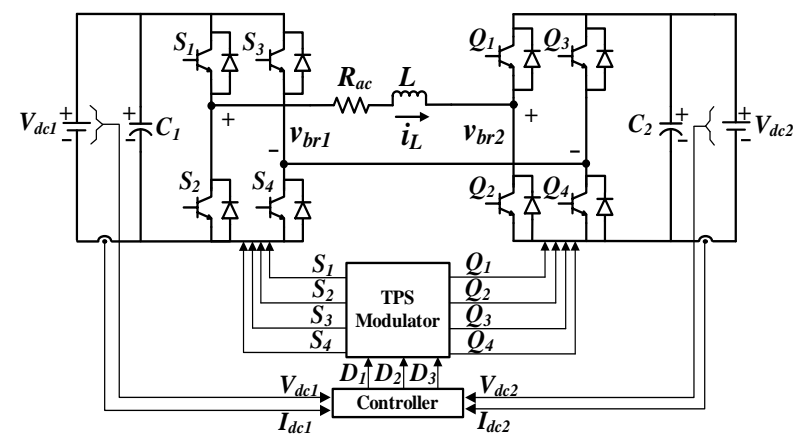

Fig. 12. Schematic of the experimental DAB topology.

\section{A. Steady state response}

Proposed control scheme is verified in this section at selected steady state reference power levels for various voltage conversion ratios $K$. Both bridge voltage $\left(V_{b r 1}, V_{b r 2}\right)$ and 
instantaneous inductor current $\left(i_{L}\right)$ are measured at the $\mathrm{AC}$ side presented in Fig. 13 where the RMS inductor is measured and displayed on the right hand side of the scope screenshot.

Comparison between experimental setup and optimal offline results in terms of phase shifts and the RMS inductor current is shown in Table IV. It can be observed that the outputs of the proposed controller $\left(D_{1}, D_{2}\right.$ and $\left.D_{3}\right)$ are closely matching the optimal phase shifts provided in section IV.

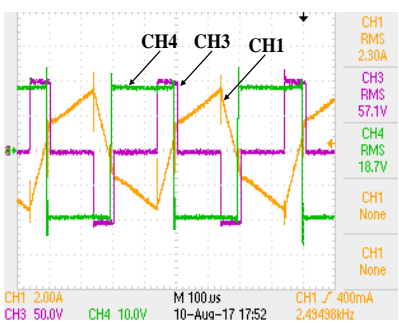

(a)

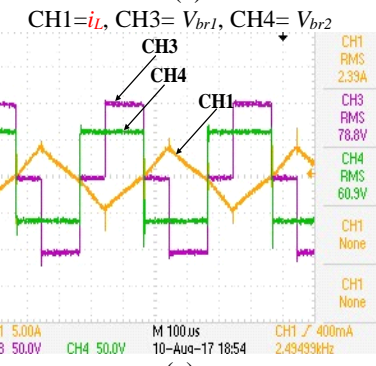

(c)

$\mathrm{CH} 1=i_{L}, \mathrm{CH} 3=V_{b r l}, \mathrm{CH} 4=V_{b r 2}$

Fig. 13. Voltage of both bridges and inductor current $\left(V_{b r 1}, V_{b r 2}, i_{L}\right)$ readings at the AC link from the experimental setup:

(a) $K=0.2, P^{*}=-0.08 \mathrm{pu}$, (b) $K=0.4, P^{*}=0.15 \mathrm{pu}$.

(c) $K=0.6, P^{*}=-0.24 \mathrm{pu}$, (d) $K=1, P^{*}=0.5 \mathrm{pu}$.

TABLE IV

COMPARISON BETWEEN EXPERIMENTAL SETUP AND OPTIMAL OFFLINE RESULTS

\begin{tabular}{|c|c|c|}
\hline \multirow{2}{*}{$K, P^{*}$} & \multicolumn{2}{|c|}{ Phase shifts/Inductor current } \\
\cline { 2 - 3 }$K=0.2, P^{*}=-0.08 \mathrm{pu}$ & From experimental setup & From PSO offline (optimal) \\
\cline { 2 - 3 }$K=0.4, P^{*}=0.15 \mathrm{pu}$ & $D_{l}=0.263, D_{2}=1, D_{3}=-0.74$ & $D_{I}=0.246, D_{2}=1, D_{3}=-0.78$ \\
\hline \multirow{2}{*}{$K=0.6, P^{*}=-0.24 \mathrm{pu}$} & $i_{L R M S}=2.3 \mathrm{~A}=\mathbf{0 . 4 6} \mathbf{~ p u}$ & $\operatorname{Min} i_{L R M S}=\mathbf{0 . 4 4} \mathbf{~ p u}$ \\
\cline { 2 - 3 } & $i_{L R M S}=2.07 \mathrm{~A}=\mathbf{0 . 4 1 4} \mathbf{~ p u}$ & Min $i_{L R M S}=\mathbf{0 . 4 1 2} \mathbf{~ p u}$ \\
\cline { 2 - 3 }$K=1, P^{*}=0.5 \mathrm{pu}$ & $i_{L R M S}=2.39 \mathrm{~A}=\mathbf{0 . 4 7 8} \mathbf{~ p u}$ & Min $i_{L R M S}=\mathbf{0 . 4 7 1} \mathbf{~ p u}$ \\
\cline { 2 - 3 } & $D_{I}=1, D_{2}=1, D_{3}=0.148$ & $D_{I}=1, D_{2}=1, D_{3}=0.146$ \\
\cline { 2 - 3 } & $i_{L R M S}=2.79 \mathrm{~A}=\mathbf{0 . 5 5 8} \mathbf{~ p u}$ & Min $i_{L R M S}=\mathbf{0 . 5 5 5} \mathbf{~ p u}$ \\
\hline
\end{tabular}

B. Comparative analysis with other phase shift methods

The proposed technique and other existing phase shift methods are applied to the experimental DAB at different conditions (voltage conversion ratio $K$ ) and at different power levels. The AC link readings $\left(V_{b r l}, V_{b r 2}, i_{L}\right.$ and $\left.i_{L R M S}\right)$ at these different conditions are presented in Fig.14, where the RMS current stresses using the proposed technique is lower than current stresses resulting from other existing techniques proving the significance of proposed technique.

\section{Experimental and theoretical comparative analysis}

For further verification of the theoretical analysis, comparative efficiency curves in experimental and theoretical (simulation) using the proposed technique are provided as depicted in Fig. 15. The efficiency calculation, outlined by (10), is carried out using the DAB parameters illustrated in Table III.

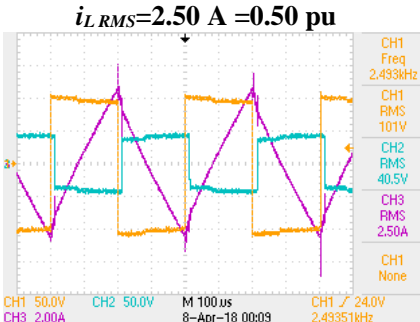

(a)

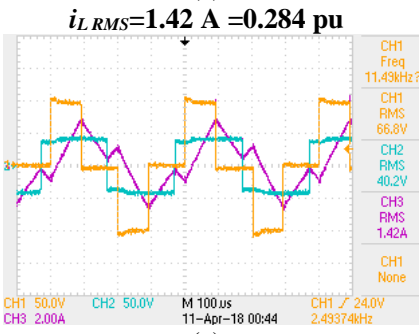

(c)

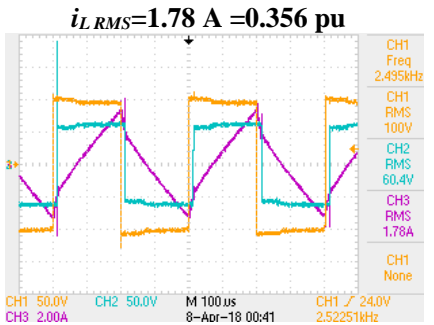

(e)

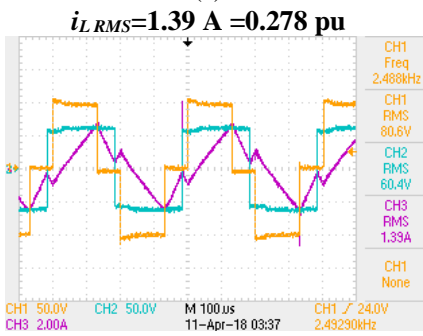

(g)

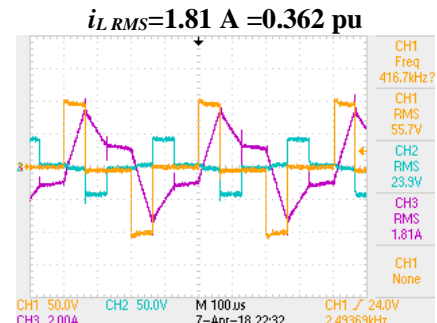

(b)

L RMS $=1.05 \mathrm{~A}=0.21 \mathrm{pu}$

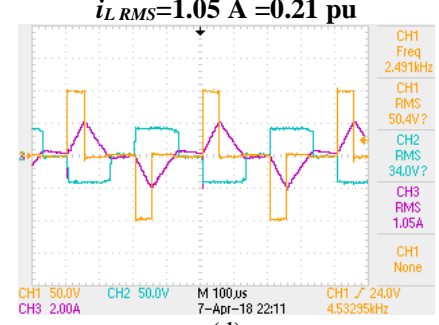

(d)

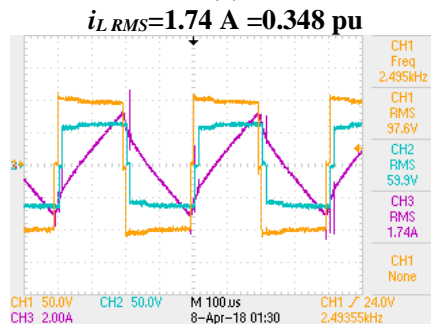

(f)

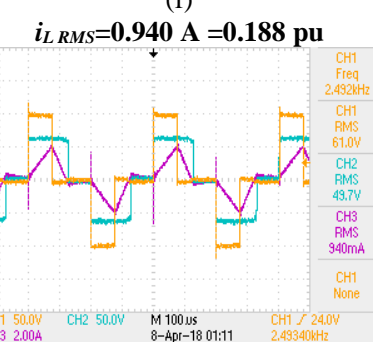

(h)
Fig. 14. Experimental comparison between the proposed technique and other existing phase shift methods $\left(\mathrm{CH} 1=V_{b r}, \mathrm{CH} 2=V_{b r 2}, \mathrm{CH} 3=i_{L}\right)$

(a)-(d) $K=0.4, P^{*}=0.08 \mathrm{pu}$, in CPS, DPS, EPS and Proposed technique respectively. (e)-(h) $K=0.6, P^{*}=0.12 \mathrm{pu}$, in CPS, DPS, EPS and Proposed technique respectively.

\section{CONCLUSION}

In this paper, a generalized per unit model of dual active bridge (DAB) converter based on the triple phase shift modulation (TPS) was developed. On the basis of this generic model which can be applied to any DAB converter regardless of ratings and parameter values, particle swarm optimization (PSO) technique was used offline at first to generate the optimal phase shift ratios for the converter at the entire power level and different values of voltage conversion ratios. The optimal phase shift ratios obtained from this offline optimization exercise were analyzed and useful patterns were identified and utilized to design a simple closed loop controller for real time power regulation of the DAB converter. The control algorithm was developed with the objective of achieving the required power transfer level while minimizing AC current stress. Besides, the proposed control scheme can be implemented without carrying out any of the offline PSO work, as the optimized relations/functions obtained from it are final and ready for implementation. The simulation and experimental results validate the effectiveness of the proposed generic controller. 


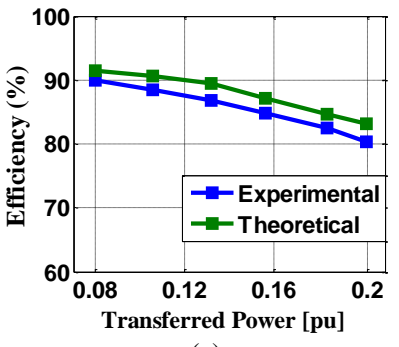

(a)

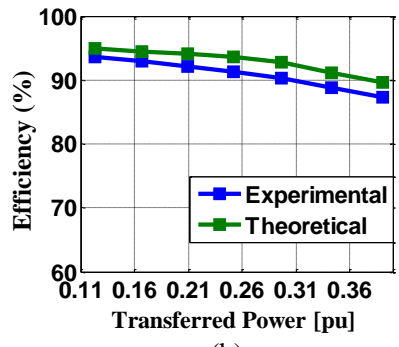

(b)
Fig.15. Efficiency calculated in experimental and simulation using the proposed technique: (a) at $K=0.2$, (b) at $K=0.4$

\section{REFERENCES}

[1] R. W. A. A. De Doncker, D. M. Divan and M. H. Kheraluwala, "A three-phase soft-switched high-power-density DC/DC converter for high-power applications," in IEEE Transactions on Industry Applications, vol. 27, no. 1, pp. 63-73, Jan/Feb 1991. [2] B. Zhao, Q. Song, W. Liu and Y. Sun, "Overview of Dual-Active-Bridge Isolated Bidirectional DC-DC Converter for High-Frequency-Link Power-Conversion System," in IEEE Transactions on Power Electronics, vol. 29, no. 8, pp. 4091-4106, Aug. 2014.

[3]B. Zhao, Q. Song, J. Li, Q. Sun and W. Liu, "Full-Process Operation, Control, and Experiments of Modular High-Frequency-Link DC Transformer Based on Dual Active Bridge for Flexible MVDC Distribution: A Practical Tutorial," in IEEE Transactions on Power Electronics, vol. 32, no. 9, pp. 6751-6766, Sept. 2017. [4]J. Riedel, D. G. Holmes, B. P. McGrath and C. Teixeira, "Active Suppression of Selected DC Bus Harmonics for Dual Active Bridge DC-DC Converters," in IEEE Transactions on Power Electronics, vol. 32, no. 11, pp. 8857-8867, Nov. 2017.

[5]S. T. Lin, X. Li, C. Sun and Y. Tang, "Fast transient control for power adjustment in a dual-active-bridge converter," in Electronics Letters, vol. 53, no. 16, pp. 1130 $1132,832017$.

[6]M. Yaqoob, K. H. Loo and Y. M. Lai, "Extension of Soft-Switching Region of Dual-Active-Bridge Converter by a Tunable Resonant Tank," in IEEE Transactions on Power Electronics, vol. 32, no. 12, pp. 9093-9104, Dec. 2017.

[7]X. Liu et al., "Novel Dual-Phase-Shift Control With Bidirectional Inner Phase Shifts for a Dual-Active-Bridge Converter Having Low Surge Current and Stable Power Control," in IEEE Transactions on Power Electronics, vol. 32, no. 5, pp. 40954106, May 2017.

[8] W. R. Leon Garcia, P. Tixador, B. Raison, A. Bertinato, B. Luscan and C. Creusot, "Technical and Economic Analysis of the R-Type SFCL for HVDC Grids Protection," in IEEE Transactions on Applied Superconductivity, vol. 27, no. 7, pp. 1-9, Oct. 2017.

[9] A. Nisar and M. S. Thomas, "Comprehensive Control for Microgrid Autonomous Operation With Demand Response," in IEEE Transactions on Smart Grid, vol. 8, no. 5, pp. 2081-2089, Sept. 2017.

[10] B. Zhao, Q. Song, J. Li, Q. Sun and W. Liu, "Full-Process Operation, Control, and Experiments of Modular High-Frequency-Link DC Transformer Based on Dual Active Bridge for Flexible MVDC Distribution: A Practical Tutorial," in IEEE Transactions on Power Electronics, vol. 32, no. 9, pp. 6751-6766, Sept. 2017.

[11] R. Dhua, D. Chatterjee and S. K. Goswami, "Study of improved load sharing methodologies for distributed generation units connected in a microgrid," in CSEE Journal of Power and Energy Systems, vol. 3, no. 3, pp. 311-320, Sept. 2017. [12] F. Xue, R. Yu and A. Q. Huang, "A 98.3\% Efficient GaN Isolated Bidirectional DC-DC Converter for DC Microgrid Energy Storage System Applications," in IEEE Transactions on Industrial Electronics, vol. 64, no. 11, pp. 9094-9103, Nov. 2017.

[13] W. Chen, P. Rong, and Z. Y. Lu, "Snubberless bidirectional DC-DC converter with new CLLC resonant tank featuring minimized switching loss," IEEE Trans. Ind. Electron., vol. 57, no. 9, pp. 3075-3086, Sep. 2010.

[14] G. P. Adam, I. A. Gowaid, S. J. Finney, D. Holliday and B. W. Williams, "Review of dc-dc converters for multi-terminal HVDC transmission networks," in IET Power Electronics, vol. 9, no. 2, pp. 281-296, 2102016.

[15] H. Bai and C. Mi, "Eliminate Reactive Power and Increase System Efficiency of Isolated Bidirectional Dual-Active-Bridge DC-DC Converters Using Novel DualPhase-Shift Control," in IEEE Transactions on Power Electronics, vol. 23, no. 6, pp. 2905-2914, Nov. 2008.

[16]B. Zhao, Q. Yu and W. Sun, "Extended-Phase-Shift Control of Isolated Bidirectional DC-DC Converter for Power Distribution in Microgrid," in IEEE Transactions on Power Electronics, vol. 27, no. 11, pp. 4667-4680, Nov. 2012

[17] W. Kuiyuan, C. W. de Silva, and W. G. Dunford, "Stability Analysis of Isolated Bidirectional Dual Active Full-Bridge DC-DC Converter With Triple Phase-Shift Control," Power Electronics, IEEE Transactions on,vol. 27, pp. 2007-2017, 2012.

[18] J. Huang, Y. Wang, Z. Li and W. Lei, "Unified Triple-Phase-Shift Control to Minimize Current Stress and Achieve Full Soft-Switching of Isolated Bidirectional DC-DC Converter," in IEEE Transactions on Industrial Electronics, vol. 63, no. 7, pp. 4169-4179, July 2016.
[19] S. S. Muthuraj, V. K. Kanakesh, P. Das and S. K. Panda, "Triple Phase Shift Control of an LLL Tank Based Bidirectional Dual Active Bridge Converter," in IEEE Transactions on Power Electronics, vol. 32, no. 10, pp. 8035-8053, Oct. 2017.

[20] Y. A. Harrye, K. H. Ahmed, G. P. Adam and A. A. Aboushady, "Comprehensive steady state analysis of bidirectional dual active bridge DC/DC converter using triple phase shift control," 2014 IEEE 23rd International Symposium on Industrial Electronics (ISIE), Istanbul, 2014, pp. 437-442.

[21] H. Gu, D. Jiang, R. Yin, S. Huang, Y. Liang and Y. Wang, "Power characteristics analysis of bidirectional full-bridge DC-DC converter with triplephase-shift control," 2015 IEEE 10th Conference on Industrial Electronics and Applications (ICIEA), Auckland, 2015, pp. 363-368.

[22] H. Wen, W. Xiao and B. Su, "Non-active Power Loss Minimization in a Bidirectional Isolated DC-DC Converter for Distributed Power Systems," in IEEE Transactions on Industrial Electronics, vol. 61, no. 12, pp. 6822-6831, Dec. 2014. [23] Y. A. Harrye, K. H. Ahmed and A. A. Aboushady, "Reactive power minimization of dual active bridge DC/DC converter with triple phase shift control using neural network," 2014 International Conference on Renewable Energy Research and Application (ICRERA), Milwaukee, WI, 2014, pp. 566-571.

[24] N. Hou, W. Song and M. Wu, "Minimum-Current-Stress Scheme of Dual Active Bridge DC-DC Converter With Unified Phase-Shift Control," in IEEE Transactions on Power Electronics, vol. 31, no. 12, pp. 8552-8561, Dec. 2016.

[25] B. Zhao, Q. Song, W. Liu and W. Sun, "Current-Stress-Optimized Switching Strategy of Isolated Bidirectional DC-DC Converter With Dual-Phase-Shift Control," in IEEE Transactions on Industrial Electronics, vol. 60, no. 10, pp. 44584467, Oct. 2013.

[26] S. Inoue and H. Akagi, "A Bidirectional DC-DC Converter for an Energy Storage System With Galvanic Isolation," in IEEE Transactions on Power Electronics, vol. 22, no. 6, pp. 2299-2306, Nov. 2007. [27] M. Kim, M. Rosekeit, S. K. Sul and R. W. A. A. De Doncker, "A dual-phaseshift control strategy for dual-active-bridge DC-DC converter in wide voltage range," 8th International Conference on Power Electronics - ECCE Asia, Jeju, 2011, pp. 364-371

[28] F. Krismer and J. W. Kolar, "Closed form solution for minimum conduction loss modulation of DAB converters," IEEE Trans. Power Electron.,vol. 27, no. 1, pp. 174-188, Jan. 2012.

[29] J. Kennedy and R. Eberhart, "Particle swarm optimization," Neural Networks, 1995. Proceedings, IEEE International Conference on, Perth, WA, 1995, pp. 19421948 vol.4.

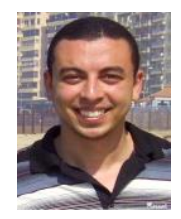

Osama M. Hebala received the B.Sc. (first class hons.) and M.Sc. degrees in electrical and control engineering from Arab Academy for Science, Technology \& Maritime Transport (AASTMT), Alexandria, Egypt, in 2011 and 2015, respectively. Osama is on leave from (AASTMT) to pursue the Ph.D. degree in electrical engineering at Robert Gordon University, Aberdeen, UK. His research interests include bidirectional DC-DC converters, power conversion systems, and power systems planning and optimization.

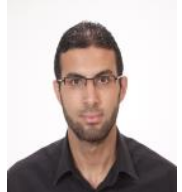

Ahmed A. Aboushady (M'04, SM'17) received his BSc (Hons) and MSc degrees in Electrical and Control Engineering from the Arab Academy for Science and Technology, Egypt in 2005 and 2008 respectively. Following this, he obtained his $\mathrm{PhD}$ degree in power electronics form the University of Strathclyde, UK in 2013. He is currently a Lecturer in power electronic systems at Glasgow Caledonian University, UK. Dr Aboushady has several publications in refereed journals/conferences as well as a published textbook, a book chapter contribution and a PCT patent No. PCT/GB2017/051364. His research interests are DC/DC converters, high voltage DC transmission systems, grid integration of renewable energy and distributed generation systems.

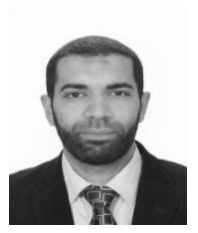

Khaled H. Ahmed (M'09, SM'12) received the B.Sc. (first class honours) and M.Sc. degrees from Alexandria University, Egypt in 2002 and 2004, respectively. He received the Ph.D. degree in power electronics applications from the University of Strathclyde, UK, 2008. He was appointed as an Associate Professor at Alexandria University, Egypt since 2014. Currently, Dr Ahmed is a Senior Lecturer in Power Electronics at the University of Strathclyde, UK. He is a senior member of the IEEE Power Electronics and Industrial Electronics societies. Dr Ahmed has published over 88 technical papers in refereed journals and conferences. His research interests are renewable energy integration, high power converters, off-shore wind energy, DC/DC converters, HVDC, and smart grids.

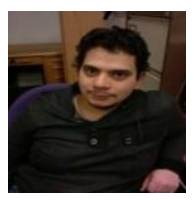

Ibrahim Abdelsalam received a first class B.Sc. and M.Sc. degrees in electrical engineering from the Arab Academy for Science and Technology and Maritime Transport (AASTMT), Egypt, in 2006(Alexandria campus) and 2009(Cairo campus). $\mathrm{He}$ received the $\mathrm{Ph} . \mathrm{D}$. degree in power electronics from University of Strathclyde, Glasgow, UK, 2016. Currently he is a lecturer in electrical engineering department at Arab Academy for Science, Technology and Maritime Transport. His research interests are power electronic converters and their applications in wind energy conversion systems, and advanced control strategies of the multilevel voltage and current source converters. 